\title{
IMAGE PROCESSING TECHNIQUES FOR ROI IDENTIFICATION IN RHEUMATOID ARTHRITIS PATIENTS FROM THERMAL IMAGES
}

\author{
Agnieszka WASILEWSKA*, Jolanta PAUK*, Mikhail IHNATOUSKI ${ }^{* *}$ \\ *Faculty of Mechanical Engineering, Department of Automatic Control and Robotics, Bialystok University of Technology, \\ ul. Wiejska 45C, 15-351 Bialystok, Poland \\ ${ }^{*}$ Scientific and Research Department, Yanka Kupala State University of Grodno, Grodno, Belarus \\ a.wasilewska@doktoranci.pb.edu.pl, j.pauk@pb.edu.pl, mii_by@mail.ru
}

received 2 October 2017, revised 5 March 2018, accepted 9 March 2018

\begin{abstract}
Rheumatoid arthritis (RA) is a systemic autoimmune disease that manifests itself by joint inflammation, swelling, pain, tenderness and may involve extra-articular organs in severe cases. Joint inflammatory lesions are associated with higher temperature due to increased vascularity in the area of inflamed tissues. This papers aimed to identify heat patterns from ROls to interpret the presence of inflammation in rheumatoid arthritis patients. The thermovisual image sequences were collected from 65 patients with Rheumatoid Arthritis (RA). Infrared images were generated by a thermal scanning camera (FLIR E60bx Systems Inc., USA). Separate recordings of left and right foot temperature changes were performed for 3 minute periods. The temperature measurement was performed at the moment right after cold water immersion (post-cooling temperature) and at the moment after thermal recovery (post-recovery temperature). The recording of 3-minute foot thermal recovery was used for analysis. Automatically identified ROI corresponds to the area of the soft tissues covering cuboid and navicular bone.
\end{abstract}

Keywords: Dynamic Thermography, Image Processing, Segmentation, Inflammation

\section{INTRODUCTION}

Rheumatoid arthritis $(\mathrm{RA})$ is a systemic autoimmune disease that manifests itself by joint inflammation, swelling, pain, tenderness and may involve extra-articular organs in severe cases (Cojocaru, 2010). The disease majorly involves the small joints of the hand and feet (Gabriel, 2001). Early diagnosis of RA is necessary as uncontrolled disease progression may lead to bone destructions and disabilities. Joint inflammatory lesions are associated with higher temperature due to increased vascularity in the area of inflamed tissues (Fernández, 2015). Thus, joint temperature comprises a promising diagnostic parameter in identifying rheumatoid arthritis. Owing to the fact that every object, including human skin, emits infrared radiation, these pathological changes can be observed with the use of Infrared thermography (IT): an imagining technique that enables detecting this emission (Tattersall, 2016). This method has received a great deal of particular attention in science and medical practice for several decades (Jones, 1998).Infrared thermography, when compared to temperature measured by contact probes, gives a distribution over a surface instead of a scalar value (Ludwig, 2014). This method of temperature measurement enables to map body surface temperature remotely (Lahiri, 2012). Its low price and non-invasiveness are primary reasons to explore the diagnostic potential of this method. In medicine usefulness of IT has been first noticed after observation of asymmetric hot spots and vascularity in thermal breast images of patients with breast cancer. The diagnostic basis of IR thermography in clinical use is the increased vascularity of pathological lesions, e.g. inflammation or neoplasms, which results in the rise of skin temperature and these changes can be detected by infrared camera (Ring, 1998). The dynamic procedure includes the application of specific stimuli, e.g. local cooling or heating on measured object. Afterwards, the evolution of surface temperature distribution is registered during the transitional process. These changes are recorded as dynamic thermogram or a sequence of thermal images. Wasilewska noted that due to additional time information and minimal dependency on external and host conditions dynamic thermography presents certain advantages over static IT (Wasilewska, 2017). In active thermography, surface temperature reacts to applied cold excitation, and these changes depend on the internal structure and inform about thermal properties of the analysed material, which poses a significant value in diagnosing subcutaneous tissues abnormalities, especially tumours and inflammatory lesions (Kaczmarek, 2016). Due to safety issues, the shape of thermal stimulus and its exposition time should be controlled. In human examinations, to avert biofeedback and reduce the influence of thermoregulatory process, no more than one-minute exposition is recommended (Kaczmarek, 2016). Wasilewska and Pauk suggested applying 5 -second cooling period in dynamic IT examinations of rheumatoid arthritis lesions as it provides discernible effects and safety examination conditions (Wasilewska, 2017). In literature, scientists indicate different medical praxis of active thermography, e.g. Purslow et al. used active thermography to analyze the effect of contact lens wear on dynamic ocular surface temperature (Purslow, 2005). Several authors presented the usefulness of active thermography in skin burn diagnostics (Renkielska, 2006; Renkielska, 2014), evaluation of cardiosurgery and postcardiosurgery wound healing (Nowakowski, 2014; Nowakowski, 2015), plastic surgery (John, 2016) or skin cancer (Herman, 2011). Thermal images lack shape and precise limits (Afshar, 2017). Infrared thermograms are usually captured in a large area, 
then the unnecessary regions and background from the thermogram images before further processing should be removed (Dey, 2017). In the aims of ROI extraction from the thermal infrared image, the ROI segmentation should be performed to partition the thermal image into multiple segments as a set of pixels or superpixels (Bezerra, 2013). After segmentation, features extraction specifies the quantifiable property of the thermal image. Typical measurements are: minimum and maximum temperatures and region statistics, e.g. averages and standard deviations (Barcelos, 2014). This papers aimed to identify heat patterns from ROls to interpret the presence of inflammation in rheumatoid patients.

\section{METHODS}

\subsection{Thermovisual images acquisition}

The thermovisual image sequences were collected from 65 patients with Rheumatoid Arthritis (RA). None of the participants had a health condition, which would impact study outcome. Inclusion criteria for patients recruited for the study included: age above 18 years old, the duration of treatment above 1 year. All subjects received full information about the study before giving signed consent. The ethical committee approved the study (Medical University of Bialystok, Poland). Infrared images were generated by a thermal scanning camera (FLIR E60bx Systems Inc., USA). The camera was calibrated by the manufacturer for reproducibility and accuracy of readings. The image resolution was $320 \times 240$ pixels. The patients stayed in seated position for 10 minutes in the examination room before the registration began. The camera was mounted on a standard camera tripod located at 1.0 meter from the skin surface. Experiments demonstrated that the most convenient cooling method for the foot is the application of ice water for 5 seconds. It cooled the skin by about 5-70C below its initial normal temperature. Separate recordings of left and right foot temperature changes were performed for 3 minute periods. The temperature measurement was performed at the moment right after cold water immersion (post-cooling temperature) and at the moment after thermal recovery (post-recovery temperature). The ambient temperature during measurements was $23^{\circ} \mathrm{C}$, relative humidity $55 \%$. Fig. 1 and Fig. 2 demonstrate thermal images post-cooling and post-recovery. Thermal recovery registration was accomplished simultaneously for healthy and unhealthy parts of the skin.

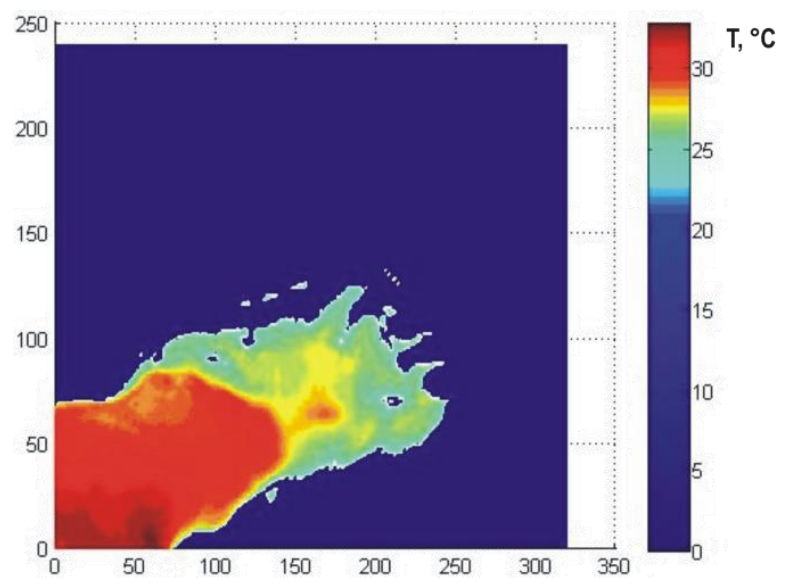

Fig. 1. Thermal image post-cooling

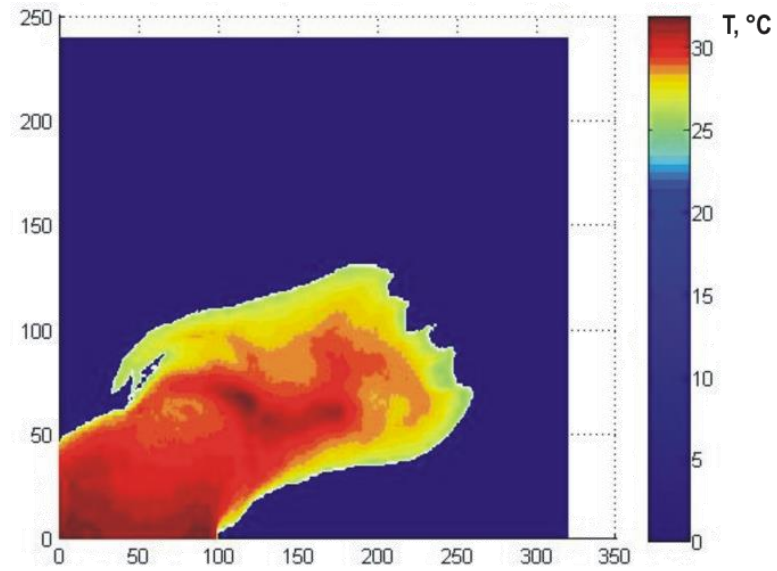

Fig. 2. Thermal image post-recovery

There are definite differences between post-cooling and postrecovery temperature distributions in the dorsal part of RA patient's foot $(p<0.05)$.

\subsection{Image processing and analysis}

The recording of 3-minute foot thermal recovery was used for analysis. The last frame's temperature distribution diagram was generated. It was bimodal with a first maximum in the standard temperature of background and second maximum in the standard temperature of the body. The local minimum between the first and second maximums was found, and it comprised the level of thresholding. Thresholding technique was used to isolate foot in the thermal image. Arithmetical mean of the temperature of the foot was calculated starting from the first frame up to the last frame. The images were segmented on the basis of a multidimensional matrix of joint occurrence of attributes (W) (Kovalev, 1996). An arbitrary pair of pixels $(i, j)$ given by indices $\left(i=\left(x_{i}, y_{i}\right)\right.$, $\mathrm{j}=\left(\mathrm{x}_{\mathrm{j}}, \mathrm{y}_{\mathrm{j}}\right)$ ) on a 2D space was analysed to construct a matrix of attributes. The distance between the pixels was $d(i, j)$. The brightness levels of the pixels were designated by I(i) , I(j). The luminance gradient modules were calculated as follow:

$G(i)=\sqrt{G_{x}^{2}(i)+G_{y}^{2}(i)}$,
$G(j)=\sqrt{G_{x}^{2}(j)+G_{y}^{2}(j)}$. follow:

The components of the gradient vectors were calculated as

$\mathrm{G}_{\mathrm{x}}=\mathrm{K}_{\mathrm{x}} \otimes \mathrm{I}(\mathrm{NB}(\mathrm{x}, \mathrm{y}))$,

$\mathrm{G}_{\mathrm{y}}=\mathrm{K}_{\mathrm{y}} \otimes \mathrm{I}(\mathrm{NB}(\mathrm{x}, \mathrm{y}))$,

where: $\mathrm{NB}(\mathrm{x}, \mathrm{y})$ - neighbourhood of the analysed pixel (size $3 \times 3$ or more). The masks of the convolution operation were Prewit, Sobel or Hummel (Zucker, 1981). The angle between the directions of the luminance gradient vectors in $2 \mathrm{D}$ space was calculated:

$A(i, j)=\arccos (g(i) \times g(j))$,

where:g(i), g(j) are normalised gradient vectors.

The six-dimensional matrix of joint occurrence of attributes combines all the listed features: 
$W=\|w(I(i), I(j), G(i), G(j), A(i, j), d(i, j))\|$.

The size of the matrix of attributes was equal to the number of pixel combinations of the image:

$\mathrm{C}=\frac{\mathrm{N} !}{2(\mathrm{~N}-2) !}$,

where: $\mathrm{N}$ is a number of pixels.

The matrix of attributes was divided into classes (f: $\mathrm{W} \rightarrow$ $\Pi(W))$ using the function (Ihnatouski, 2000):

$\mathrm{f} \rightarrow \min \left|\mathrm{W}_{\mathrm{k}} \times \mathrm{W}_{\mathrm{l}}\right|$.

The partitioning of the matrix of attributes into classes can be considered complete if for all $\mathrm{W}_{\mathrm{k}}(\mathrm{k}, \mathrm{l}=1,2, \ldots, \mathrm{C})$ performed:

$\mathrm{W}_{\mathrm{k}} \cap \mathrm{W}_{\mathrm{l}}=0(\forall \mathrm{k}, \mathrm{l})$.

\subsection{Statistical Analysis}

Descriptive statistics of maximum, minimum and mean temperatures were used for primary data analysis. Data were tested for normality with the Shapiro-Wilk test and comparisons were computed using paired-samples t-tests. Statistical analysis was performed using Statistics 13.5, and the statistical significance was set at $p<0.05$.

\section{RESULTS}

Sixty-five RA patients of both genders were analysed to perform this research work. Foot thermograms in the frontal view were taken with the FLIR E60bx camera, making a total of 130 thermal scan images. The ROI (Figs: 3,4,5) and the shin were two hottest places in the last frame. These two areas have been picked out. Then the shin area bordering on the margin of the image has been deselected. Fig. 3 presents ROI with maximal temperature selected from the first frame which corresponded to the moment right after cooling procedure.

ROI with maximal temperature (Fig. 5) was also appointed for the last image of thermal recovery registration which corresponded to steady -state temperature.

After selecting areas covered by pathological process, the area of healthy part of foot was determined. Fig. 4 presents inflamed and healthy area in the same thermal image.
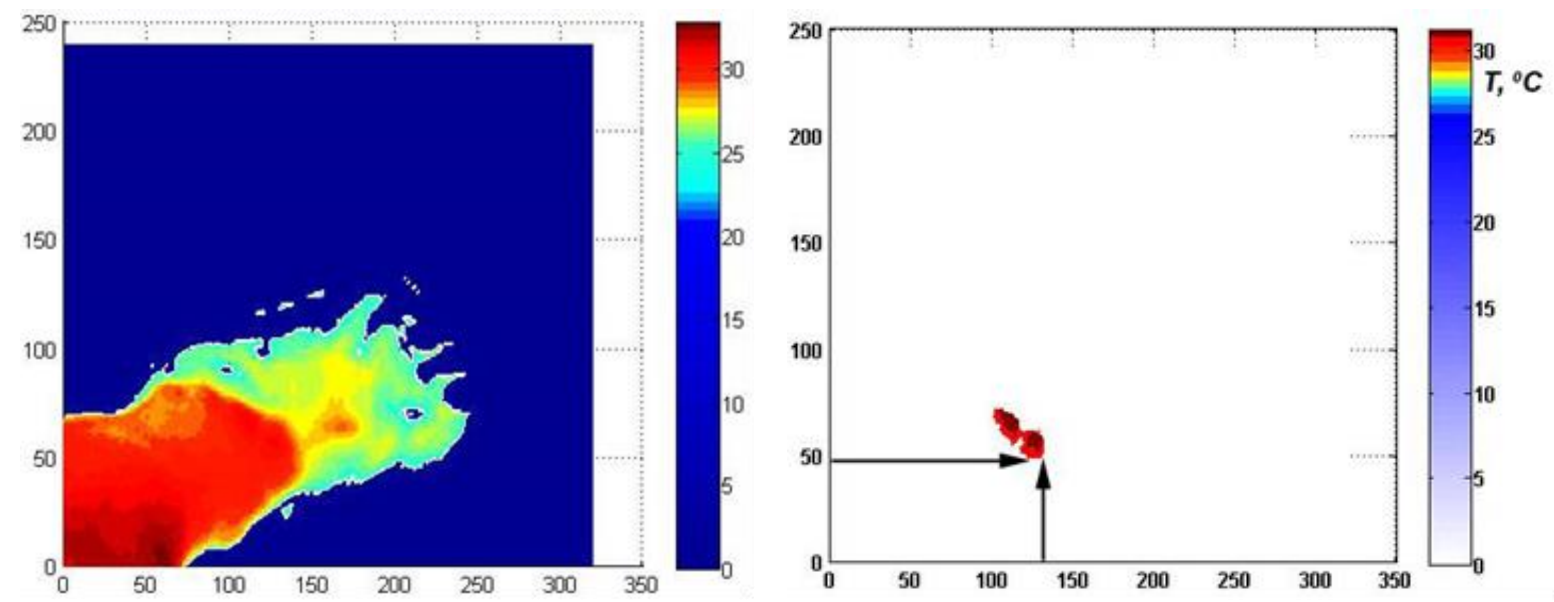

Fig. 3. ROI with Tmax from the first frame

The simultaneous rewarming process of pathological tissues and healthy tissues foregrounded the thermal differences between affected and healthy tissues. Automatically identified ROI corresponds to the area of the soft tissues covering cuboid and navicular bone. According to the scale alongside presented thermal images, selected ROI strikes as being the warmest place at the moment after cooling as well as in the moment after thermal recovery. However, after returning to baseline temperature, the area particularly affected by the disease is significantly warmer and more apparent. Fig. 6 presents the plot of temperature rise as a function of time for ROI area. Arithmetical mean of the temperature of dorsal metatarsal veins of the foot has been calculated starting from the first up to last frames.

The sample parameter values obtained from the measurements of the temperature $\left[{ }^{\circ} \mathrm{C}\right]$ in ROI for RA patients are presented in Tab. 1. Additionally, the difference between the inflamed (ROI) and healthy parts of the skin was determined.

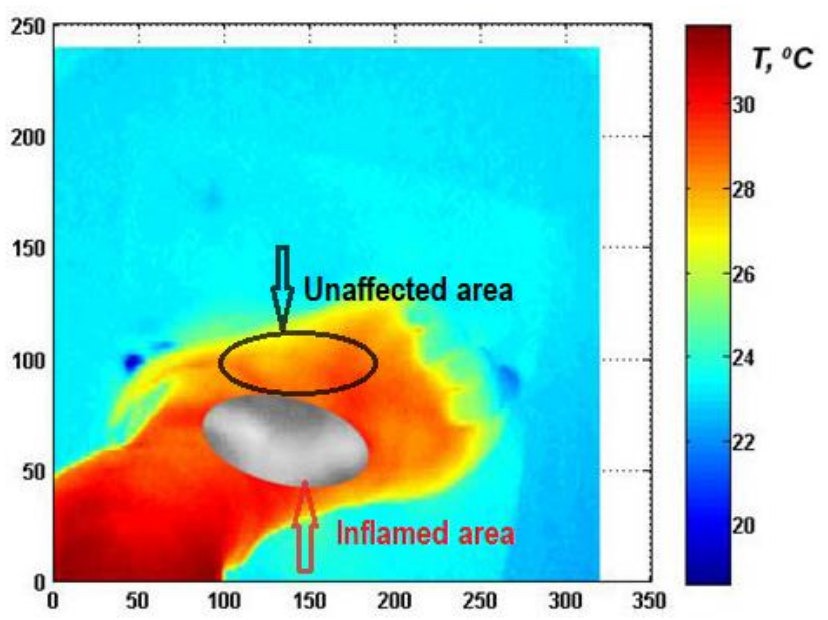

Fig. 4. The ROI post-recovery 

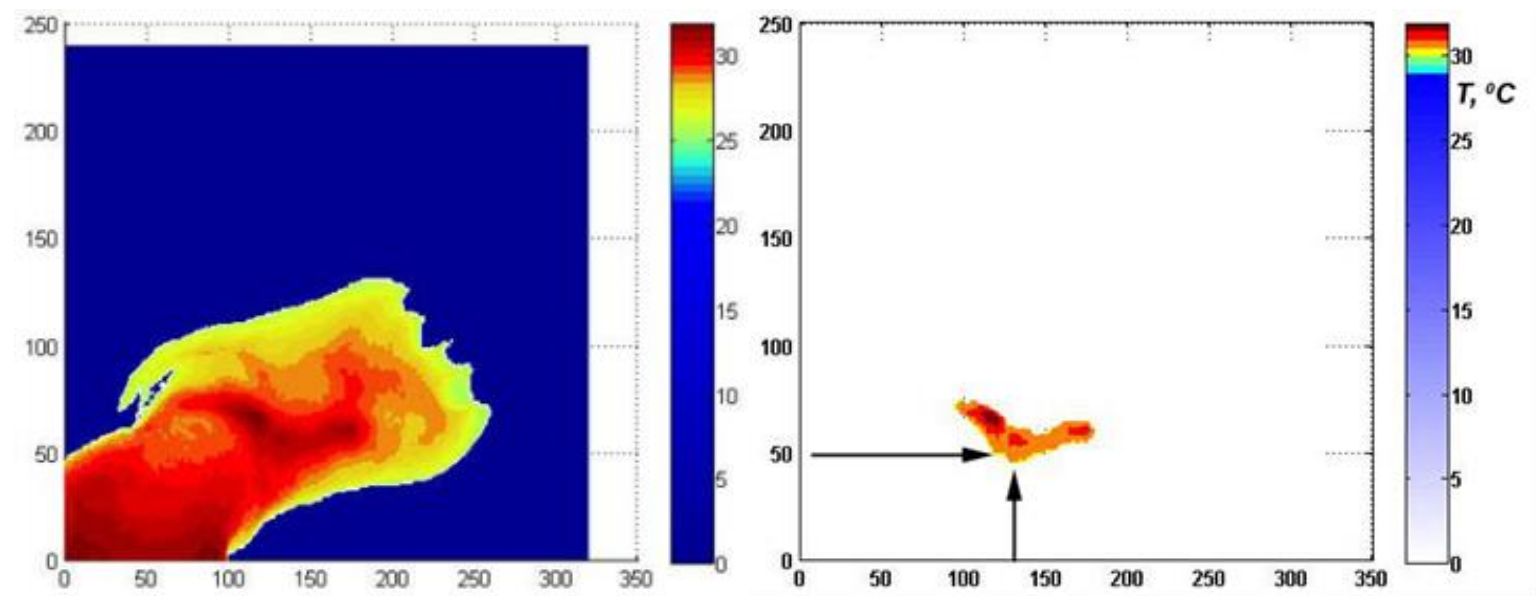

Fig 5. ROI with Tmax from last frame

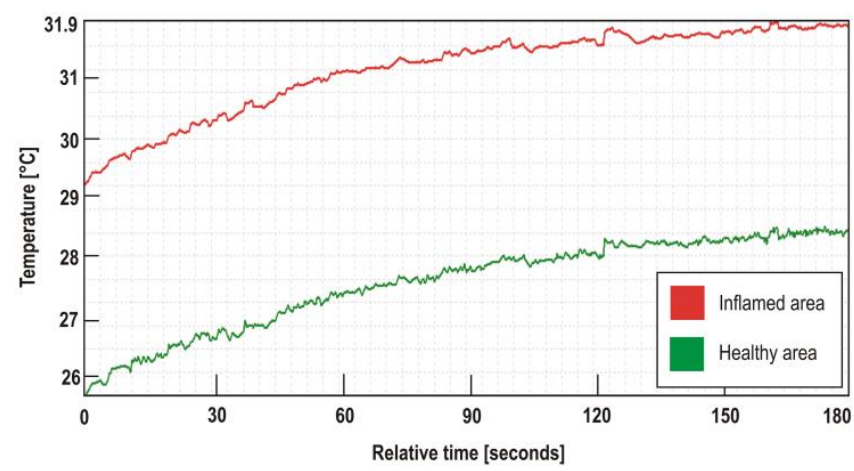

Fig. 6. Thermal response of the skin in the $\mathrm{ROI}$ area

Tab. 1. The set of parameters for the inflammation and healthy skin

\begin{tabular}{|c|c|c|c|c|c|c|}
\hline \multirow[b]{2}{*}{ Temperature } & \multicolumn{2}{|c|}{ Inflammed area } & \multicolumn{2}{|c|}{ Healthy area } & \multirow{2}{*}{\begin{tabular}{|c} 
Difference \\
in post- \\
cooling \\
temperature \\
between \\
inflamed \\
area vs \\
healthy skin
\end{tabular}} & \multirow{2}{*}{$\begin{array}{c}\text { Difference } \\
\text { in post- } \\
\text { recovery } \\
\text { temperature } \\
\text { between } \\
\text { inflamed } \\
\text { area vs } \\
\text { healthy skin }\end{array}$} \\
\hline & $\begin{array}{l}\text { Post- } \\
\text { cooling }\end{array}$ & $\begin{array}{l}\text { Post- } \\
\text { recovery }\end{array}$ & $\begin{array}{l}\text { Post- } \\
\text { cooling }\end{array}$ & $\begin{array}{l}\text { Post- } \\
\text { recovery }\end{array}$ & & \\
\hline Minimum & 23.60 & 25.60 & 20.40 & 23.50 & \multirow{3}{*}{$2.31^{*}$} & \multirow{3}{*}{$2,22^{*}$} \\
\hline Maximum & 30.20 & 33.80 & 28.20 & 32.10 & & \\
\hline $\begin{array}{c}\text { Mean } \\
\text { (SD) }\end{array}$ & $\begin{array}{l}27.81 \\
(1.93)\end{array}$ & $\begin{array}{l}30.61 \\
(1.84)\end{array}$ & \begin{tabular}{|l|}
25.53 \\
$(1.89)$ \\
\end{tabular} & $\begin{array}{l}28.42 \\
(1.83)\end{array}$ & & \\
\hline
\end{tabular}

${ }^{*} p<0.05$

The results show several regularities. The difference in postcooling temperature between inflamed area and healthy tissues is statistically significant with the higher temperature for the prior $(p<0.05)$. Similarly, statistically significant difference between inflamed and healthy part of the foot occurs also in post-recovery temperature, with the higher temperature for the abnormal tissues $(p<0.05)$. The post-recovery temperature is higher for the inflamed part as well as for healthy part of the skin when compared to the post-cooling temperature, with the higher temperature for the abnormal tissues $(p<0.05)$. The post-recovery temperature is higher for the inflamed part as well as for healthy part of the skin when compared to the post-cooling.

\section{CONCLUSIONS}

The analysis of thermal images usually includes the manual or semi-automatic extraction of ROI provided by commercial software. In this study, we developed a method which allows identifying automatically a region of interest (ROI) on thermal images based on proposed segmentation algorithm. Results revealed statistically significant differences between inflamed and healthy area in post cooling temperature as well as in post recovery temperature. Thus, the method can be used in effective assessment of inflammation in RA patients.

\section{REFERENCES}

1. Afshar S., Sheehan M. (2017), Applying infrared thermography and image analysis to dilute 2-phase particulate systems: Hot Particle Curtains, Energy Procedia, 110, 408-413.

2. Barcelos Z.E., Caminhas W.M., Ribeiro E., Pimenta E.M., Palhares R.M. (2014), A combined method for segmentation and registration for an advanced and progressive evaluation of thermal images, Sensors, 14, 21950-21967.

3. Bezerra H.G., Attizzani G.F., Sirbu V., Musumeci G., Lortkipanidze N., Fujino Y., Wang W., Nakamura S., Erglis A., Guagliumi G., Costa M.A. (2013), Optical coherence tomography versus intravascular ultrasound to evaluate coronary artery disease and percutaneous coronary intervention, JACC Cardiovasc Interv., 6(3), 228-36.

4. Cojocaru M., Cojocaru I.M., Silosi I., Vrabie C.D., Tanasescub R., (2010), Extra-articular manifestations in rheumatoid arthritis; Maedica (Buchar), 5(4), 286-291.

5. Dey N., Ashour A.S., Chakraborty S., Banerjee S., Gospodinova E., Gospodinov M., Hassanien A.E. (2017), Watermarking in biomedical signal processing, Intelligent Techniques in Signal Processing for Multimedia Security, Dey N, Santhi V (eds); Springer International Publishing, 345 -369.

6. Fernández-Cuevas I., Bouzas Marins J.C., Arnáiz Lastras J., Gómez Carmona P.M., Piñonosa Cano S., García-Concepción M.A., Sillero-Quintana M. (2015), Classification of factors influencing the use of infrared thermography in humans: a review, Infrared Physics \& Technology 71, 28-55.

7. Gabriel S.E. (2001), The epidemiology of rheumatoid arthritis, Rheum Dis Clin North Am., 27(2), 269-81.

8. Herman C., Pirtini Cetingul M. (2011, Quantitative visualization and detection of skin cancer using dynamic thermal imaging, J. Vis. Exp., $51,1-4$. 
9. Ihnatouski M.I. (2000), Methods of segmentation of AFM and STM images. Recognition and description of cluster surface objects in the nanoscale IV Belarusian seminar on scanning probe microscopy (SPM-4). V.A. Belyi Metal Polymer Research Institute: 122-126.

10. John H.A., Niumsawatt V., Rozen W.M., Whitaker I.S. (2016), Clinical applications of dynamic infrared thermography in plastic surgery: a systematic review, Gland Surg, 5(2), 122-132.

11. Jones B.F. (1998), A re-appraisal of the use of infrared thermal image analysis in medicine, IEEE Trans Med Imaging, 17,1019-27.

12. Kaczmarek M., Nowakowski A. (2016), Active IR-thermal imaging in medicine, J Nondestruct Eval, 35(19), 1-16.

13. Kovalev V., Petrou M. (1996), Multidimensional co-occurrence matrices for object recognition and matching, Graphical Models and Image Processing., 58(3), 187-197.

14. Lahiri B.B., Bagavathiappan S., Jayakumar T. (2012), Medical applications of infrared thermography, A review, Infrared Physics \& Technology, 55(4), 221-235.

15. Ludwig N., Formenti D., Gargano M., Alberti G. (2014), Skin temperature evaluation by infrared thermography: comparison of image analysis methods, Infrared Physics \& Technology, 62,1-6.

16. Nowakowski A., Siondalski P., Moderhak M., Kaczmarek M. (2014), Problems of cardiosurgery wound healing evaluation, Proceedings of QIRT, 1-9.

17. Nowakowski A., Siondalski P., Moderhak M., Kaczmarek M. (2015), A new diagnostic method for evaluation of cardiosurgery wound healing, JQIRT, 1-16.

18. Purslow C., Wolffsohn J.S., Santodomingo-Rubido J. (2005), The effect of contact lens wear on dynamic ocular surface temperature, Contact Lens \& Anterior Eye, 28, 29-36.

19. Renkielska A., Kaczmarek M., Nowakowski A., Grudzinski J., Czapiewski P., Krajewski A., Grobelny I. (2014), Active dynamic infrared thermal imaging in burn depth evaluation, J. Burn Care Res, 35(5), 294-303.
20. Renkielska A., Nowakowski A., Kaczmarek M., Ruminski J. (2006), Burn depths evaluation based on active dynamic IR thermal imaging-a preliminary study, Burns, 32, 867-875.

21. Ring E.F.J. (1998), Progress in the measurement of human body temperature, IEEE Eng Med Biol, 17, 19-24.

22. Tattersall G.J. (2016), Infrared thermography: non-invasive window into thermal physiology, Comp Biochem Physiol A Mol Integr Physiol, 202, 78-98.

23. Wasilewska A. (2017), Advantages of active over passive thermography in terms of applying in medicine, Scientific and didactic equipment, 22(2), 88-93.

24. Wasilewska A., Pauk J. (2017), Safety conditions in dynamic IT examinations of rheumatoid arthritis lesions, Scientific and didactic equipment, 22(3), 205-214.

Acknowledgements: The work has been accomplished under the research project No. MB/WM/19/2016 financed by the Bialystok University of Technology. 